\title{
Beyond Flex Time: Retaining Female Scientists and Engineers
}

\section{Lynne Robinson}

Editor's Note: A more comprehensive version of this article can be found on the Materials@TMS web site.

Imagine the repercussions if a company routinely lost access to half of its most promising resources, even after investing a fortune in their development. According to "The Athena Factor: Reversing the Brain Drain in Science, Engineering, and Technology," a groundbreaking study published by the Harvard Business Review in June 2008, this is exactly the case with the retention of female scientists and engineers. The study found that, while women constitute 41 percent of all science, engineering, and technology professionals at the lower rungs of the career ladder, more than 50 percent of them eventually leave, with the peak of the exodus at around the ten-year career mark.

Providing input from the mining and metals industry on this issue was Pittsburgh-based Alcoa, one of the study's co-sponsors. "We really brought a different perspective," said Judi Nocito, assistant general counsel and co-leader of the Alcoa Women's Network. "We have unique challenges because we are in heavy industry. The result is that we struggle in attracting and retaining women, especially in operating roles within the company."

The Athena Factor study was conducted by the Center for Work-Life Policy (CWLP), an independent, nonprofit research organization headquartered in New York. Alcoa's involvement with the project began when it joined with 35 other global corporations to form CWLP's Hidden Brain Drain Task Force. The task force, formed in 2004, has spearheaded a number of studies on sustaining female and minority talent. Alcoa was particularly interested in the Athena Factor, however, because of its focus on women in science and engineering positions. "Prior to this work, we as a company had largely anecdotal information on the career challenges faced by women in operating roles in plants or in technical and engineering roles," said Nocito. "Data provide credibility to the issues."

As a co-sponsor, Alcoa opened its doors to CWLP researchers who conducted focus groups with women in engineering and technical fields at the Alcoa technical center in Pittsburgh, as well as its operations in Chicago, Russia, Australia, Western Europe, and Beijing. An electronic survey was also conducted of 2,300 male and female Alcoa employees with science or engineering degrees.

The study found that a number of factors contribute the departure of women from science and engineering positions, the study found. These include workplace cultures that are dismissive and even hostile toward female scientists and engineers, and hours and expectations that are not supportive of working mothers. The study called attention to the sense of isolation that many women experience when they are the only female at their level or on their team, as well as the frustration that many women feel because of unclear channels to information, opportunities, and career advancement.

The Athena Factor did muster some good news, however, by describing 14 programs that have started to demonstrate some success in not only retaining, but enabling women to advance in their careers. Highlighted among them was Alcoa's Women in Operations Virtual Extended Network (WOVEN), a pilot tested in the company's Global Primary Products Group (GPPG). Tar- geted to women in operations roles with science, engineering, and technology backgrounds, WOVEN gives female professionals, who are not close geographically, the opportunity to meet and support one another virtually as they pursue their careers. Helping women make the transition to operations from other departments in the GPPG is another WOVEN goal.

A related effort being piloted in the GPPG is Alcoa's Manufacturing Manager Development Program. Although not limited to women, the program does address issues related to career advancement and isolation raised in the Athena Factor report by methodically preparing junior candidates for line management careers. This is accomplished by developing a well-planned and monitored program for each participant that offers exposure to different divisions and different types of management experience. The goal is that the candidate will be ready to take on a plant manager role within six to eight years after joining the company.

"When you look at the Athena Factor data as a whole, the women surveyed do not seem to perceive clear career paths," said Nocito. "They feel that they don't even have the chance to throw their hat into the ring because they are not aware of opportunities or don't have a mentor or network available to them. This goes hand-in-hand with the sense of isolation-that they are on their own.

"What this program offers women is a clear career plan so they can anticipate where they are going and can stay "in the loop" from a networking standpoint."

Lynne Robinson is the news writer for Materials Technology@TMS. 